\title{
Characterization and gene expression analysis of novel matched primary and metastatic renal cell carcinoma cell lines
}

\author{
YOSHIO OHNO ${ }^{1}$, MIKI IZUMI ${ }^{2}$, MASAAKI TACHIBANA ${ }^{1}$, TAKESHI KAWAMURA ${ }^{3}$, KUNIHIKO YOSHIOKA ${ }^{1}$, \\ TEIICHIRO AOYAGI ${ }^{1}$, MAKOTO OHORI ${ }^{1}$, KAZUNORI NAMIKI ${ }^{1}$, NOBORU SAKAMOTO ${ }^{1}$, \\ YOSHIHIRO NAKAGAMI $^{1}$, TADASHI HATANO ${ }^{1}$, SHINGO AKIMOTO ${ }^{3}$ and TOSHIHIDE NISHIMURA ${ }^{3}$ \\ ${ }^{1}$ Department of Urology, ${ }^{2}$ Department of Diagnostic Pathology, ${ }^{3}$ Clinical Proteome Center, \\ Tokyo Medical University, 6-7-1 Nishishinjuku, Shinjuku-ku, Tokyo 160-0023, Japan
}

Received February 12, 2008; Accepted May 23, 2008

DOI: 10.3892/or_00000034

\begin{abstract}
Despite recent advances in molecular biology that have clarified the mechanisms involved in the metastasis of several types of cancer, the molecular mechanism underlying the metastasis of renal cell carcinoma (RCC) remains unclear. Two RCC cell lines were successfully established from the surgical specimens of a matched primary tumor and adrenal metastasis from the same RCC patient, and were designated as TMK-1P and TMK-1M, respectively. Extensive characterization was accomplished using various methods, including the Matrigel invasion assay, DNA microarray analysis and real-time reverse transcriptase (RT)-polymerase chain reaction (PCR). While TMK-1P grew faster than TMK-1M, the invasive ability of TMK-1M was higher than that of TMK-1P. DNA microarray analysis showed a large differential expression of genes related to cell adhesion and the extracellular matrix molecules of which hexabrachion (tenascin-C), epidermal growth factor receptor, cadherin-6, and B1-catenin were down-regulated, and the $67 \mathrm{kDa}$ laminin receptor 1 and transforming growth factor- $\beta$-induced $68 \mathrm{kDa}$ protein (ßig-h3) were up-regulated in TMK-1M. Real-time RT-PCR analysis confirmed this differential gene expression between the two cell lines. The RCC cell lines may be useful in studying tumor invasion and screening markers for metastasis.
\end{abstract}

\section{Introduction}

Renal cell carcinoma ( $\mathrm{RCC}$ ) is the most common malignant tumor of the kidney and accounts for $3 \%$ of adult malignancy (1). Advances in diagnostic modalities have increased the

Correspondence to: Dr Yoshio Ohno, Department of Urology, Tokyo Medical University, 6-7-1 Nishishinjuku, Shinjuku-ku, Tokyo 160-0023, Japan

E-mail: yoshio-o@tokyo-med.ac.jp

Key words: renal cell carcinoma, cell line, adrenal metastasis, DNA microarray detection rate of incidental kidney cancer. A majority of these cancers are localized within the kidney. However, after nephrectomy, metastasis occurs in $20-30 \%$ of patients with the localized disease (2). In addition, approximately one-third of patients with RCC already have metastatic disease at the time of diagnosis (3). As a result, more than half of patients with RCC suffer from metastatic disease during their clinical course. RCC preferentially metastasizes to the lung, liver, bone, adrenal gland and brain (4). RCC is resistant to cytotoxic agents and hormones, and until recently, the only effective treatment for metastatic disease was cytokine-based therapy with interferon $\alpha$ or interleukin-2 (5). Advances in the molecular biology of RCC have led to the development of new agents that target critical gene products downstream of the von Hippel-Lindau tumor suppressor (pVHL) and hypoxiainducible factor pathway, such as the vascular endothelial growth factor and epidermal growth factor receptor (6).

We succeeded in establishing two RCC cell lines from a matched primary tumor and adrenal metastasis pair. In this study, following the characterization of the novel RCC cell lines, we compared the gene expression profiles, including the hypoxia-inducible factor pathway, in the cell lines. There was a notable difference in the morphology, growth and invasiveness between the 2 cell lines. Gene expression analysis revealed a differential expression of genes related to cell adhesion and extracellular matrix molecules in the two cell lines. The novel cell lines may be useful in studying tumor invasion and molecular-targeted therapy as an in vitro experimental model.

\section{Materials and methods}

Cell source. The cancer cells used in this study were obtained from a 57-year-old male patient with renal cell carcinoma. The patient had undergone right nephrectomy for a renal tumor and developed left adrenal metastasis a year after the nephrectomy. The left adrenal tumor was also removed surgically. The primary tumor of the right kidney was histologically diagnosed as grade 3 RCC with a sarcomatoid component (pT3aN0M0, TNM system in 1997), and the left adrenal tumor was diagnosed as adrenal metastasis of RCC. Informed consent regarding the use of these specimens was obtained from the patient according to institutional guidelines. 
Table I. The primer sequences used in Real-time RT-PCR and RT-PCR.

\begin{tabular}{|c|c|c|c|}
\hline & Size of product & Forward & Reverse \\
\hline \multicolumn{4}{|l|}{ Real-time RT-PCR } \\
\hline B-actin & 89 & 5'-ATTGCCGACAGGATGCAGA-3' & 5'-GAGTACTTGCGCTCAGGAGGA-3' \\
\hline Tenascin $\mathrm{C}$ & 74 & 5'-TATGATCCAGACCATCTTCACCACA-3' & 5'-TCAGCATTGCTTGGGAGCAG-3' \\
\hline EGFR & 103 & 5'-GTGGCGGGACATAGTCAGCA-3' & 5'-CCCATTGGGACAGCTTGGA-3' \\
\hline ß1-catenin & 117 & 5'-GCTGATCTTGGACTTGATATTGGTG-3' & 5'-GTCCATACCCAAGGCATCCTG-3' \\
\hline \multicolumn{4}{|l|}{ Transforming growth factor, } \\
\hline ß-induced, 68 kDa, (ßig-h3) & 179 & 5'-TCCTGAAATACCACATTGGTGATGA-3' & 5'-GACATGGACCACGCCATTTG-3' \\
\hline Laminin receptor 1 (67 kDa) & 151 & 5'-CTTGCAGCAGGAACCCACTTAG-3' & 5'-CAATGGCAACAATTGCACGA-3' \\
\hline \multicolumn{4}{|l|}{ Angiogenesis-related genes } \\
\hline VEGF receptor 2 (KDR) & 430 & 5'-CGTCATGGATCCAGATGAACTCCC-3' & 5'-CTTGACGGAATCGTGCCCCTTTGG-3' \\
\hline $\mathrm{HIF}-1 \alpha$ & 351 & 5'-GACAAGCCACCTGAGGAGAG-3' & 5'-GAAGTGGCAACTGATGAGCA-3' \\
\hline Carbonic anhydrase IX (CA9) & 469 & 5'-CACTCCTGCCCTCTGACTTC-3' & 5'-GCTGGCTTCTCACATTCTCC-3' \\
\hline GAPDH & 294 & 5'-CGAGATCCCTCCAAAATCAA-3' & 5'-TGTGGTCATGAGTCCTTCCA-3' \\
\hline
\end{tabular}

Tissue culture method. Under aseptic conditions, tumor tissue samples from the primary tumor and adrenal metastasis were minced into $\sim 1 \mathrm{~mm}^{3}$ samples in a petri dish. The tissues were then placed in a $25-\mathrm{cm}^{2}$ culture flask containing $3.5 \mathrm{ml}$ of culture medium (RPMI-1640, Gibco, Grand Island, NY, USA) supplemented with $10 \%$ heat-inactivated fetal calf serum (FCS, Gibco), 1\% insulin-transferrin-sodium selenite medium supplement (Sigma, St. Louis, MO, USA), and $100 \mu \mathrm{g} / \mathrm{ml}$ streptomycin (Sigma) and maintained at $37^{\circ} \mathrm{C}$ in a humidified atmosphere with $5 \% \mathrm{CO}_{2}$.

The cells were sub-cultured at a split ratio of 2:1 every 6-10 days. The culture medium was replaced every 2-3 days. When the cells formed a confluent layer, they were harvested using $0.25 \%$ trypsin with $0.1 \mathrm{mM}$ EDTA and seeded at a split ratio of $5: 1$.

Cells at passage number 20 were subsequently cloned by the limiting dilution method. In brief, the cells were diluted in the culture medium as described above and adjusted to a cell density of $\sim 20$ cells $/ \mathrm{ml}$ of the suspension. Subsequently, $1 \mathrm{ml}$ of the cell suspension medium was seeded into the $35-\mathrm{mm}$ culture dishes and cultured. When the cells formed colonies, each colony was scraped with a cell scraper (BD Labware, Franklin Lakes, NJ, USA), the colony was seeded into a $25-\mathrm{cm}^{2}$ tissue culture flask containing $3.5 \mathrm{ml}$ of the culture medium and further incubated at $37^{\circ} \mathrm{C}$ in a humidified atmosphere with $5 \% \mathrm{CO}_{2}$.

Morphological and growth kinetic studies. The cells grown in a $25-\mathrm{cm}^{2}$ culture flask were observed daily using a phasecontrast microscope. For a light microscopic examination, the cells grown in a 2-well Lab-Tek chamber ${ }^{\mathrm{TM}}$ slide (Nalge Nunc International, Rochester, NY) were fixed with $100 \%$ methanol and stained with Giemsa solution.

The normal growth curves were determined by seeding $5 \times 10^{4}$ cells onto 6-well multi-well plates (BD Biosciences, Franklin Lakes, NJ). The plates were harvested, and the viable cells counted daily in a hemocytometer by dye exclusion with $0.4 \%$ trypan blue solution (Sigma, T8154). By examining 6 duplicate wells per point, the mean number of cells per well plotted at each time point was calculated. The doubling time of the cell population was estimated in the logarithmic growth phase.

In order to determine the saturation density, $10^{5}$ cells of each cell line were seeded in a $25-\mathrm{cm}^{2}$ culture flask. The cells that formed a confluent monolayer were isolated by trypsinization, and the number of cells was counted. Based on this count, the saturation density was calculated. To measure the plating efficiency, $10^{3}$ cells were plated in triplicate on $100-\mathrm{mm}$ culture dishes which were stained with $0.5 \%$ crystal violet solution (Sigma) 1 week following seeding. Colonies containing $>50$ cells were counted.

Electron microscopy. The cultured monolayer cells were fixed with $1 \%$ glutaraldehyde for $1 \mathrm{~h}$ and then post-fixed in $2 \% \mathrm{OsO}_{4}$, also for $1 \mathrm{~h}$. Ultrathin sections were stained with uranyl acetate and lead citrate. The specimens were then observed using a Hitachi H-300 electron microscope.

Chromosome analysis. For chromosome observation, the cells at passage number 30 in the exponential growth phase were treated with $0.1 \mathrm{mg} / \mathrm{ml}$ colcemid for $4 \mathrm{~h}$. The cells were harvested, exposed to hypotonic treatment $(75 \mu \mathrm{mol} / \mathrm{l} \mathrm{KCl})$ for $20 \mathrm{~min}$ and fixed with methanol-glacial acetic acid $(3: 1)$. Slide preparations of the cells were air dried, stained with Giemsa solution, and scored for the number of chromosomes presented in each of the metaphase cells.

In vitro cell invasion assay. Tumor cell invasiveness was determined by using BioCoat Matrigel Invasion Chambers (BD Biosciences, Bedford, MA, USA), which consist of a 24-well tissue culture plate and cell culture inserts (Matrigel). The Matrigel insert contains an $8-\mu \mathrm{m}$ pore size polyethylene 


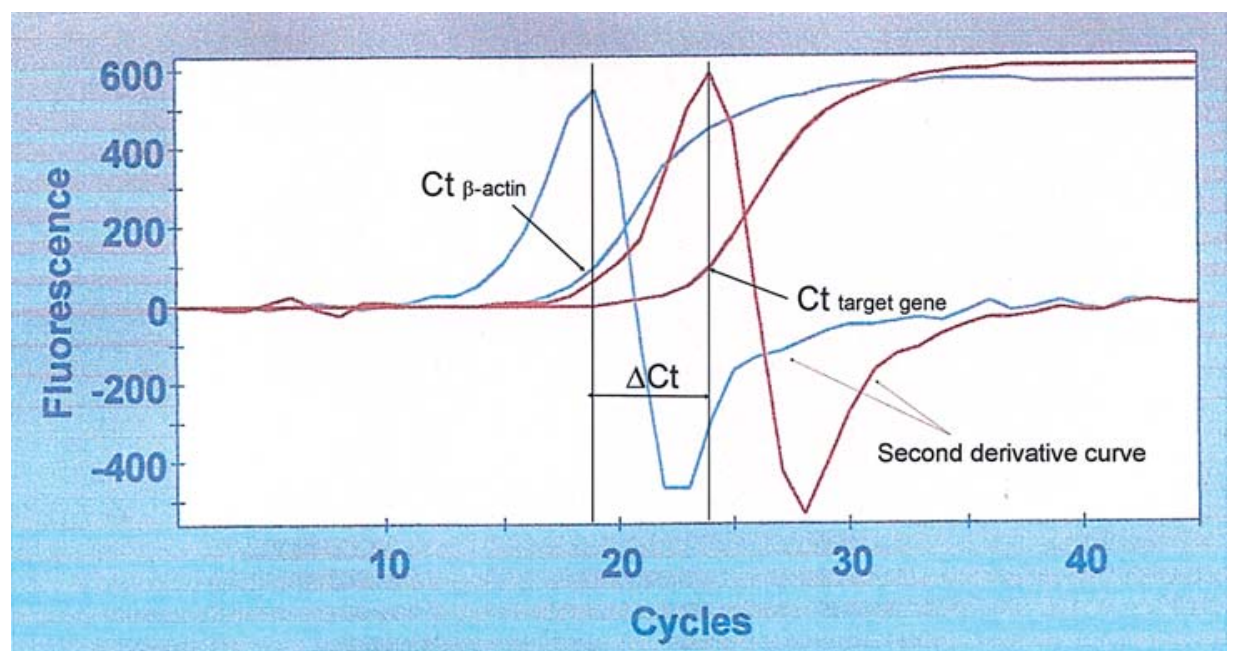

Figure 1. PCR amplification and second derivative curves by real-time RT-PCR. In the second derivative method, Ct corresponds to the first peak of the second derivative curve. This peak corresponds to the beginning of a log-linear phase.

terephthalate membrane coated with a thin layer of Matrigel basement membrane matrix, which is composed of laminin, collagen IV, heparan sulfate proteoglycans and entactin. We also used an $8-\mu \mathrm{m}$ pore size polyethylene terephthalate membrane as a control insert. In brief, the cells that were suspended in serum-free culture medium (RPMI-1640 supplemented with $100 \mu \mathrm{g} / \mathrm{ml}$ streptomycin) were added to the Matrigel and control inserts. Culture medium (750 $\mu \mathrm{l})$ containing $10 \%$ fetal bovine serum was used as a source of chemoattractants and was added to the wells of the tissue plate. Each insert was transferred to the wells containing the chemoattractant. The chambers were incubated at $37^{\circ} \mathrm{C}$ in a humidified atmosphere at $5 \% \mathrm{CO}_{2}$ for 24 or $48 \mathrm{~h}$. Following incubation, the non-invading cells were removed from the upper surface of the membrane by wiping with a cotton swab. The cells on the lower surface of the membrane were stained with $4 \%$ crystal violet. The membrane was removed from the insert and mounted onto a glass slide. The number of cells was counted under a light microscope at 200x magnification. Invasiveness was assayed in triplicate for each cell line and by a minimum of 3 independent experiments. The data were expressed as the percent invasion through the Matrigel matrix and membrane relative to the migration through the control membrane. Percent invasion $=$ the mean number of cells invading through the Matrigel insert membrane/the mean number of cells migrating through the control insert membrane.

cDNA microarray analysis. cDNA microarray analysis was conducted to screen for the differential gene expression between the 2 cell lines. The total RNA from each cell line that was harvested at $70-80 \%$ confluence was extracted using the Isogen reagent (Nippon Gene, Toyama, Japan) according to the manufacturer's instructions. Poly (A)+ mRNA was prepared from the total RNA using the Oligotex ${ }^{\mathrm{TM}}-\mathrm{MAG}$ mRNA purification kit (Takara Biomedical, Tokyo, Japan). Poly (A) $)^{+}$mRNA $(1 \mu \mathrm{g})$ from TMK-1P or TMK-1M was annealed to oligo dT(18) and transcribed using AMV reverse transcriptase in the presence of Cy3- or Cy5-tagged dUTP (Amersham Biosciences, San Francisco, CA), respectively. Labelled cDNA probes were mixed with hybridization solution (6x standard saline citrate [SSC], $0.2 \%$ sodium dodecyl sulfate [SDS], 5x Denhardt's solution, and $0.1 \mathrm{mg} / \mathrm{ml}$ denatured salmon sperm DNA. They were subsequently hybridized to the cDNA microarray (IntelliGene Human Cancer CHIP version 2.0; Takara Biomedical) at $65^{\circ} \mathrm{C}$ for $12.5 \mathrm{~h}$. The slides were washed for $30 \mathrm{~min}$ in $2 \mathrm{x} \mathrm{SSC}$ and $0.2 \% \mathrm{SDS}$ at $55^{\circ} \mathrm{C}$ twice, $5 \mathrm{~min}$ in $2 \mathrm{x} \mathrm{SSC}$ at $65^{\circ} \mathrm{C}$ and $10 \mathrm{~min}$ in $0.05 \mathrm{x} \mathrm{SSC}$ at room temperature.

Detection of the fluorescence intensities was carried out using a GMS 418 array scanner (Affymetrix, Santa Clara, CA). The data were analyzed by ImaGene software version 3.02 (BioDiscovery, El Segundo, CA). The IntelliGene ${ }^{\mathrm{TM}}$ Human Cancer CHIP contains 425 cancer-related genes, 11 housekeeping genes ( $ß$-actin, glyceraldehyde-3-phosphate dehydrogenase and $\alpha 2$ tubulin), and genes of non-human species (pUC19, E. coli ompA, E. coli cysS and Arabidopsis cellulose synthase). The signal intensity of each spot was considered to be significant if the mean signal intensity was greater than twice the mean signal intensity of pUC19. The signal intensity was normalized to the averaged signals of the housekeeping genes. Gene expression was quantified as the TMK-1P (Cy3): TMK-1M (Cy5) ratio. According to previous studies $(7,8)$, values of $\geq 2.0$ or $\leq 0.5$ were considered to be indicative of differential expression.

Real-time $R T-P C R$. To verify the difference in gene expression that was observed in the microarray, a real-time reverse transcriptase (RT)-polymerase chain reaction (PCR) was performed. We chose the 6 representative genes of hexabrachion (tenascin-C), epidermal growth factor receptor $(E G F R)$ and cadherin-6 (CDH6), B1-catenin, transforming growth factor (TGF)-ß-induced $68 \mathrm{kDa}$ protein (Big-h3), and the $67 \mathrm{kDa}$ laminin receptor 1 gene. $\beta$-actin was run in each $\mathrm{PCR}$ reaction and was used as an internal control. The primer sets used are listed in Table I.

Real-time RT-PCR was performed using a SmartCycler ${ }^{\circledR}$ system (Cephied, Sunnyvale, CA). RT-PCR was carried out using a one-step RNA PCR kit (Perfect real-time, Takara Biomedical, Tokyo, Japan) according to the manufacturer's instructions. The total RT-PCR reaction volume was $25 \mu 1$ 

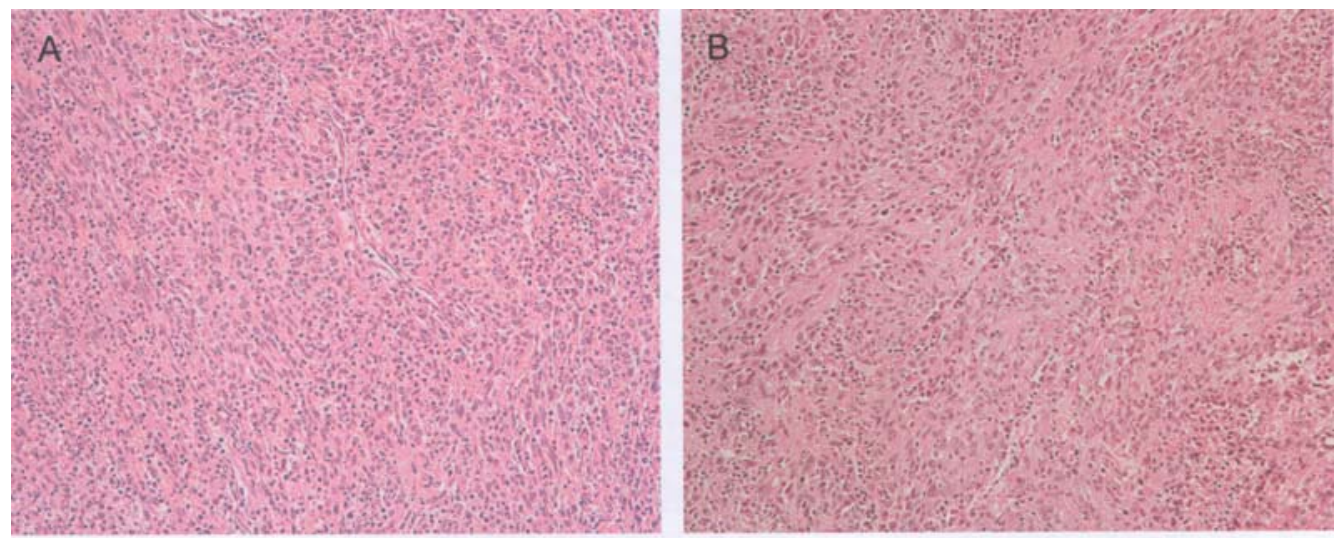

Figure 2. Histological examination of a surgical specimen. (A) The primary tumor was diagnosed as a grade 3 renal cell carcinoma with sarcomatoid cell components. HE staining, x200. (B) The left adrenal tumor was diagnosed as adrenal metastasis of the renal cell carcinoma. HE staining, x200.
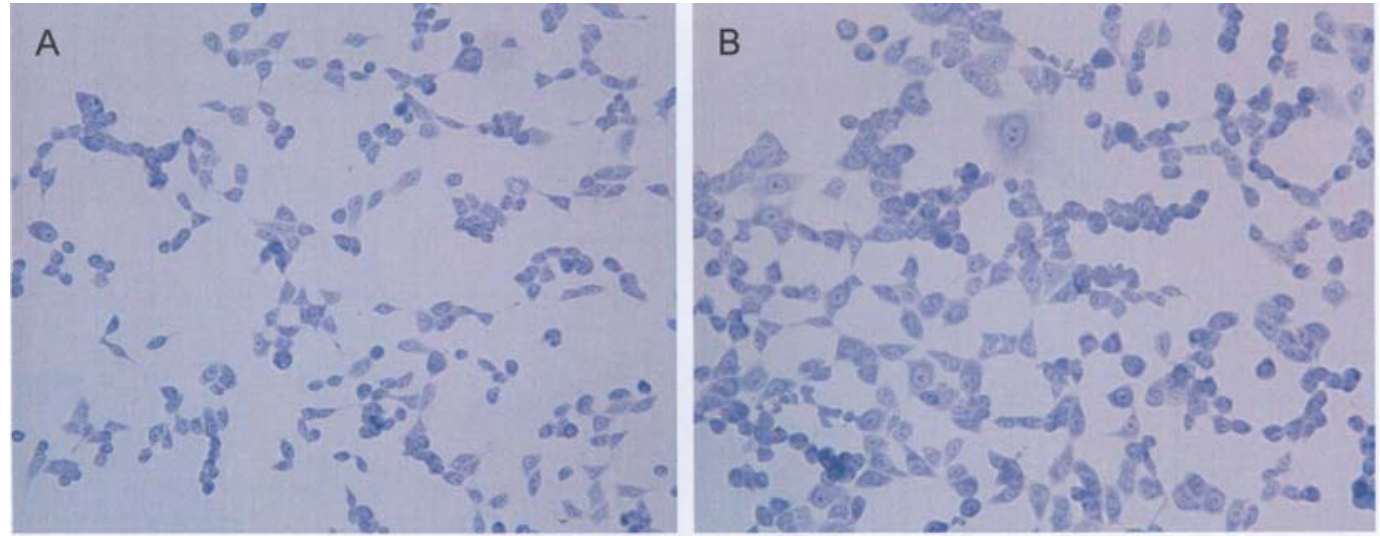

Figure 3. Microscopic observation of TMK-1P and TMK-1M. (A) The cultured TMK-1P cells show a relatively spindle-shaped cytoplasm. Giemsa staining, x200. (B) The cultured TMK-1M cells show a relatively spindle-shaped cytoplasm and are larger in size than the TMK-1P cells. Giemsa staining, x200.

and contained 1x real-time RNA PCR buffer (containing the dNTP mixture and $\mathrm{Mg}^{2+}$ ), 2.5 units Takara Ex Taq ${ }^{\mathrm{TM}} \mathrm{HS}$ polymerase, 50 units M-MLV RTase, 20 units RNase inhibitor, 3000x SYBR ${ }^{\circledR}$-Green I, 10 ng of sample RNA and $200 \mathrm{nM}$ of each oligonucleotide primer. The initial steps of RT-PCR were performed for $15 \mathrm{~min}$ at $42^{\circ} \mathrm{C}$ followed by a 2 min hold at $95^{\circ} \mathrm{C}$. Thereafter, 45 cycles consisting of a $5 \mathrm{sec}$ melt at $95^{\circ} \mathrm{C}$, followed by a $1 \mathrm{~min}$ annealing/extension at $60^{\circ} \mathrm{C}$ were performed. The denaturation curve was drawn at the end of the reaction to confirm the melting temperature of the specific PCR product.

The cycle threshold $(\mathrm{Ct})$ value, which is the cycle number at the point where the fluorescence rises above the background noise, was determined using the second derivative method (9). In this method, the $\mathrm{Ct}$ corresponds to the first peak of a second derivative curve. This peak corresponds to the beginning of a log-linear phase (Fig. 1). The relative amount of target gene transcript normalized to the internal control was determined by the difference in their $\mathrm{Ct}$ value $(\Delta \mathrm{Ct})(10)$ :

$$
\Delta \mathrm{Ct}=\mathrm{Ct}_{\text {B-actin }}-\mathrm{Ct}_{\text {target gene }}
$$

Therefore, the $\Delta \mathrm{Ct}$ value is inversely proportional to the amount of a target mRNA transcript. After 3 independent measurements, the fold difference in target gene mRNA in
TMK-1P compared to that in TMK-1M was calculated assuming that it was a $100 \%$ efficient PCR:

Fold difference $=2\left[\left(\mathrm{Ct}_{1 \mathrm{P}(\mathrm{B} \text {-actin })}-\mathrm{Ct}_{1 \mathrm{P}(\text { target })}\right)-\left(\mathrm{Ct}_{1 \mathrm{M}(\mathrm{B} \text {-actin })}-\mathrm{Ct}_{1 \mathrm{M} \text { (target) })}\right)\right]$

$\mathrm{Ct}_{1 \mathrm{P} \text { (target) }}$ and $\mathrm{Ct}_{1 \mathrm{M} \text { (target) }}$ represent the $\mathrm{Ct}$ values for the target gene of the TMK-1P and TMK-1M samples, respectively. $\mathrm{Ct}_{1 \mathrm{P}(\mathrm{B} \text {-actin) }}$ and $\mathrm{Ct}_{1 \mathrm{M}(\mathrm{B} \text {-actin) }}$ represent the $\mathrm{Ct}$ values for the $\mathrm{B}$-actin gene of the TMK-1P and TMK-1M samples, respectively.

Analysis of the hypoxia-inducible factor pathway genes by $R T-P C R$. Expression of the hypoxia-induced pathway genes of the vascular endothelial growth factor $(V E G F)$, vascular growth factor receptor 2 (VEGFR-2), hypoxia-inducible factor $1 \alpha(H I F 1 \alpha)$, and carbonic anhydrase IX (CA9) gene were analyzed by RT-PCR. Primer sets used in RT-PCR are listed in Table I. PCR with the VEGF primer set amplified 4 isoforms of VEGF mRNA: VEGF ${ }_{121}(243 \mathrm{bp}), \mathrm{VEGF}_{165}$ (375 bp), $\operatorname{VEGF}_{189}\left(447 \mathrm{bp}\right.$ ) and $\operatorname{VEGF}_{206}$ (498 bp) fragments (11). The glyceraldehyde-3-phosphate dehydrogenase gene was used as an internal control. RT-PCR was performed using Ready-to-Go RT-PCR beads (Amersham Biosciences, Piscataway, NJ) according to the manufacturer's instructions. The first-strand complementary DNA synthesis reaction was primed with the $\mathrm{pd}(\mathrm{N})_{6}$ random primer. The RT-PCR program 


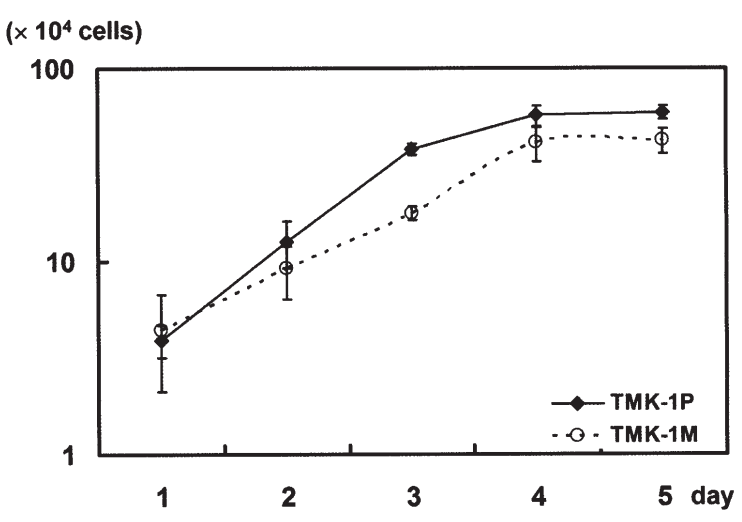

Figure 4. The growth curve of TMK-1P and TMK-1M.

was as follows: $42^{\circ} \mathrm{C}$ for $30 \mathrm{~min}, 95^{\circ} \mathrm{C}$ for $5 \mathrm{~min}$, followed by 30 cycles of $95^{\circ} \mathrm{C}$ for $1 \mathrm{~min}, 55^{\circ} \mathrm{C}$ for $1 \mathrm{~min}, 72^{\circ} \mathrm{C}$ for $1.5 \mathrm{~min}$ and a final elongation step of $72^{\circ} \mathrm{C}$ for $10 \mathrm{~min}$. The RT-PCR products were run on $2 \%$ agarose gels containing ethidium bromide and photographed under UV illumination.

Statistical analysis. The data values are expressed as means ( \pm SD). Statistical significance was determined by Student's t-test. $\mathrm{P}<0.05$ was considered significant.

\section{Results}

Establishment and characteristics of primary and metastatic cell lines. Fig. 2A and B show the histological sections of the original primary kidney cancer and adrenal metastasis. An outgrowth of cells was observed 20 days after the primary culture of the primary tumor and adrenal metastasis. The primary culture cells of the two tissues achieved confluence within 1 month. The cells at passage number 20 were subsequently subcloned by the limiting dilution method. After subcloning, one subcloned cell line was selected from each of the primary culture cells for their favorable propagation. The subcloned cell lines of the primary tumor and the adrenal metastasis were designated as TMK-1P and TMK-1M, respectively. These cell lines have been propagated continuously by serial passaging over the past year.

The growth of the cultured cells of the two cell lines had a cobblestone-like appearance and tended to pile up after achieving confluence. The cells showed prominent nucleoli, a high nucleus/cytoplasm ratio, and a relatively spindle-shaped cytoplasm. The cells of the TMK-1M cell line were larger in size than those of the TMK-1P cell line (Fig. 3A and B). The growth curve is shown in Fig. 4. The doubling time of TMK-1P and TMK-1M was estimated as 24 and $27 \mathrm{~h}$, respectively. The saturation density and plating efficiency were $7.08 \times 10^{4}$ cells $/ \mathrm{cm}^{2}$ and $18.7 \%$, respectively, in TMK-1P and $3.29 \times 10^{4}$ cells $/ \mathrm{cm}^{2}$ and $1.9 \%$, respectively, in TMK-1M.

Transmission electron microscopy. Ultrastructurally, TMK-1P cells exhibited numerous microvilli on the cell surfaces and had oval-shaped nuclei. The cytoplasm contained sparse organelles. The tight junctions were clearly demonstrated at a higher magnification (Fig. 5). Conversely, TMK-1M cells showed few microvilli on the cell surfaces and had irregularly shaped nuclei. The cytoplasm contained abundant glycogen particles. The tight junctions were seen at a higher magnification (Fig. 6).

Karyotype analysis. Fifty metaphases were counted in TMK-1P. The number of chromosomes varied from 64 to 72 , and the modal number was 69 . The G-banded karyotype was $65-70<3 n>, X X Y,-Y[4], \operatorname{add}(X, p 11)[3],+1[8],+1[4]$ $\operatorname{del}(1, \mathrm{q} 12)[7],+2[8],-4[10],+\operatorname{del}(5, \mathrm{p} 11)[7], \operatorname{del}(5, \mathrm{p} 11)[10]$,

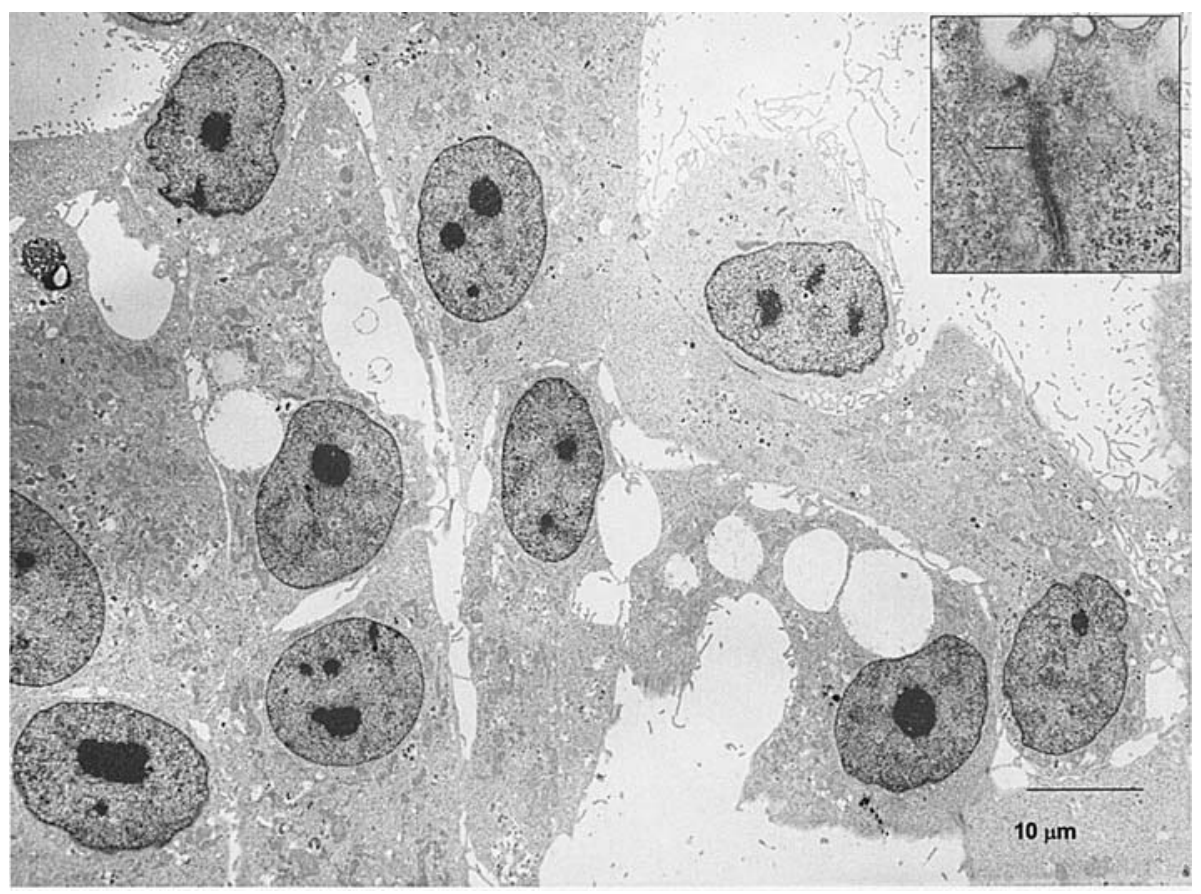

Figure 5. Transmission electron microscopic observation of cultured TMK-1P whose cells have numerous microvilli on their cell surface (x1000). A tight junction (arrow) is clearly observed at a higher magnification (inset, x25000). 


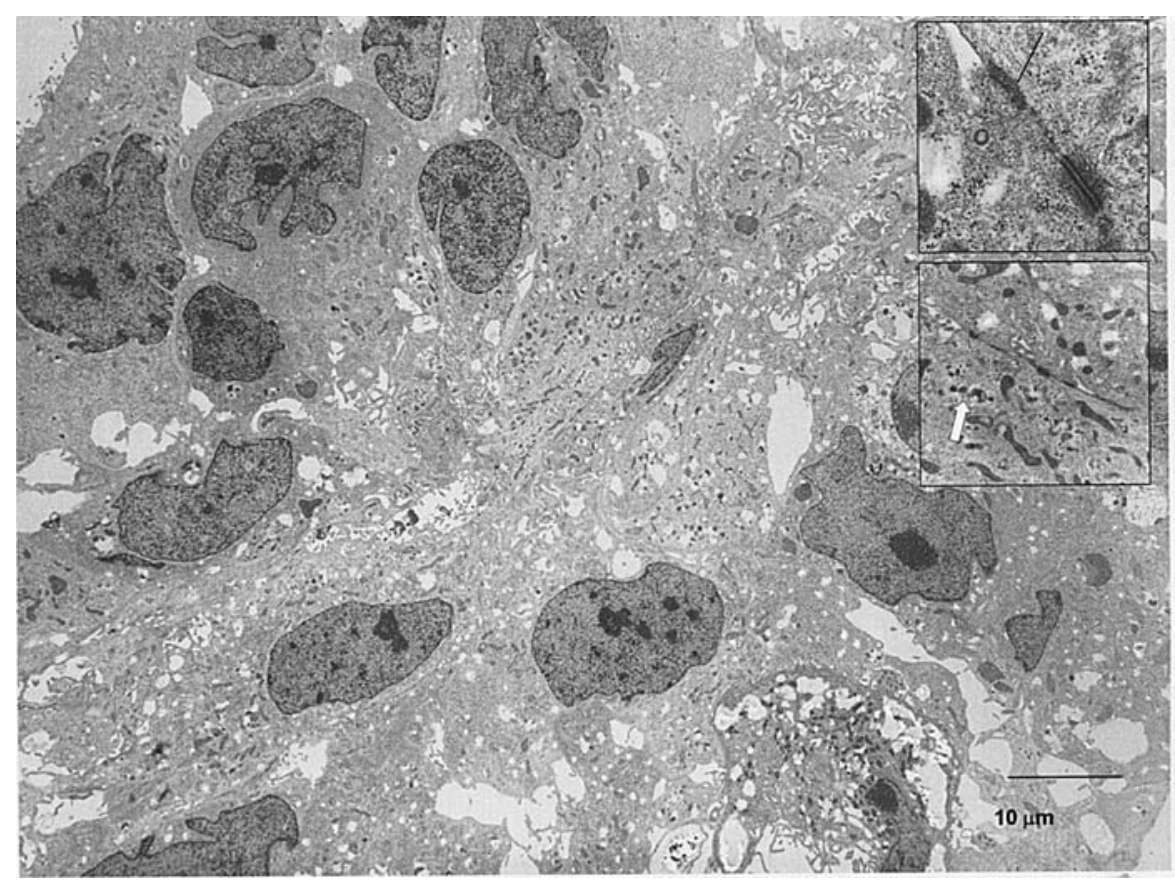

Figure 6. Transmission electron microscopic observation of cultured TMK-1M whose cells have irregularly shaped nuclei (x1000). Tight junctions (arrow) and desmosomes (white dotted arrow) are observed at a higher magnification (upper inset, x25000). The cytoplasm contains abundant glycogen particles (white arrow, lower inset, x8000).

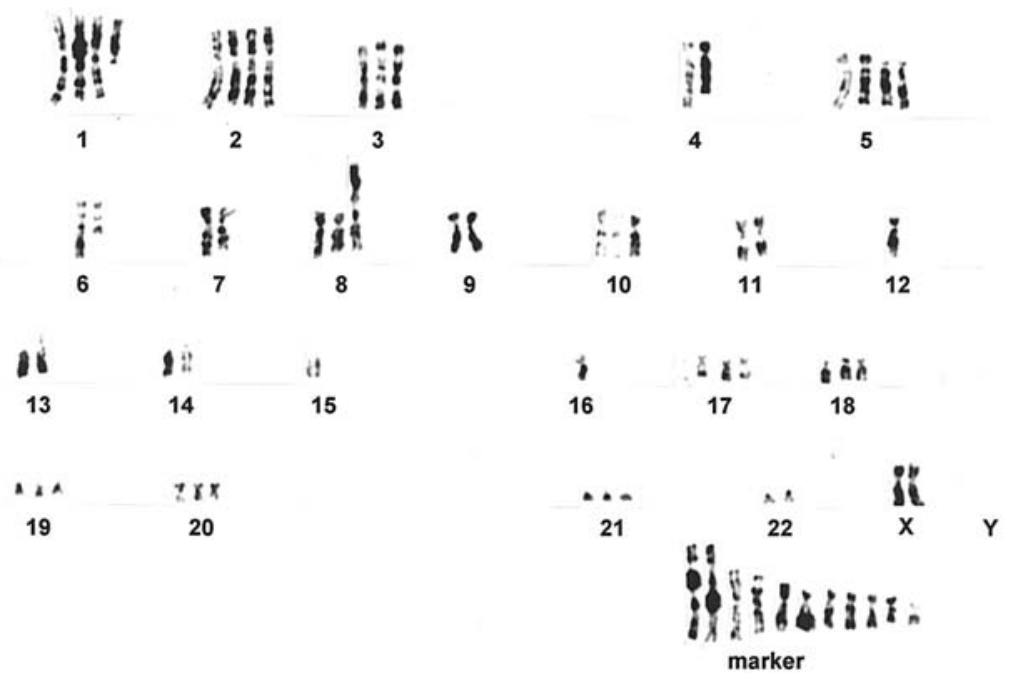

Figure 7. The chromosome analysis of TMK-1P.

$-6[8], \operatorname{add}(6, \mathrm{q} 13)[2], \operatorname{del}(6, \mathrm{q} ?)[3],-7[9], \operatorname{add}(8, \mathrm{p} 11)[10]$, $-9[8],+10[5],-11$ [9], $\operatorname{add}(11, \mathrm{q} 13)$ [2] , +12[2], -12[4], -13[10], $-14[10],-15[9], \operatorname{add}(15, \mathrm{p} 11)[2],-16[8],+17[2],-18[7]$, +20[6], -21[6], -22[7], +3-11mar (Fig. 7).

Similarly, 50 metaphases were counted in TMK-1M. The number of chromosomes varied from 57 to 74 , and the modal number was 70 . The G-banded karyotype was $68-72<3 \mathrm{n}>$, $\mathrm{XX},-\mathrm{Y}[10],+1[5],+2[8],+3[10],-4[10],+\operatorname{del}(5, \mathrm{p} 11)[2]$, $\operatorname{add}(5, \mathrm{p} 13)[3], \operatorname{del}(5, \mathrm{p} 11)[10],+6[4], \operatorname{del}(6, \mathrm{q} ?)[2],-7[10]$, $+8[2], \operatorname{add}(8, \mathrm{p} 11)[6], \operatorname{add}(8, \mathrm{p} 11)[2],-9[10],+10[7],+12[8]$, $-13[9],-14[10],-14[3],-15[10],+16[8],+17[5], \operatorname{add}(17$, p11)[8], add(17, p11)[7], +18[3], -19[5], +20[7], -21 [6], -22[6], +1-6mar (Fig. 8).
In vitro cell invasion assay. Considering each saturation density, the number of cells added into each upper chamber was $2 \times 10^{5}$ in TMK-1P and $1.5 \times 10^{5}$ in TMK-1M. The percent invasion of TMK-1M was 54.5 at $24 \mathrm{~h}$ and 67.7 at $48 \mathrm{~h}$ which was significantly higher when compared with the 1.2 and $26.9 \%$ invasion in TMK-1P $(\mathrm{P}<0.05$, Fig. 9$)$.

Identification of differentially expressed genes between $T M K-1 P$ and TMK-1M. The signals of 348 TMK-1P genes and those of 361 TMK-1M genes were considered to have a significant intensity. Compared with TMK-1M, 149 TMK-1P genes were up-regulated and 17 TMK-1P genes were downregulated. The major differential genes (cases wherein the 


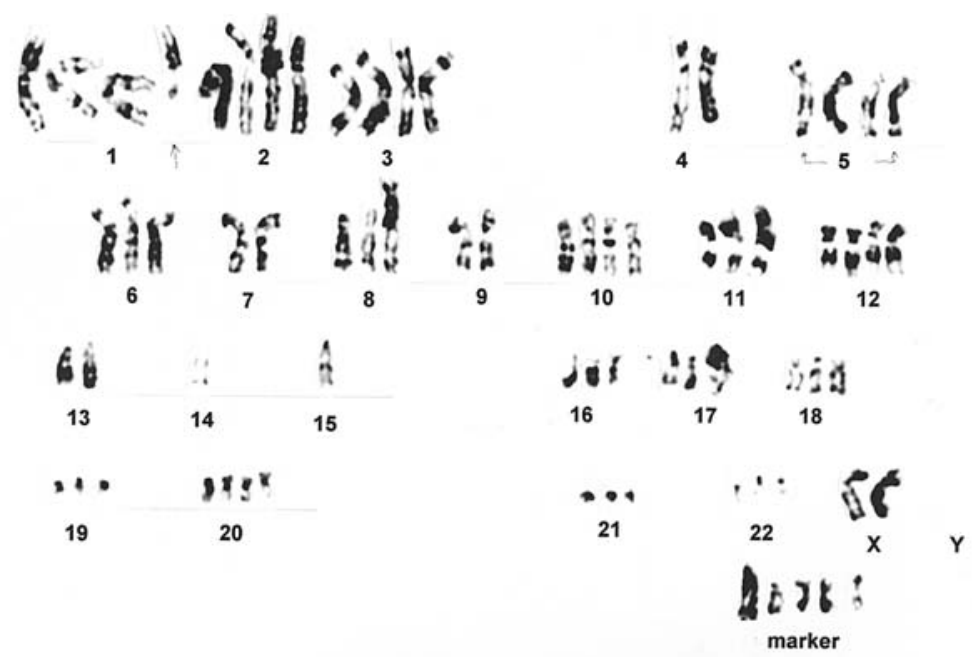

Figure 8 . The chromosome analysis of TMK-1M.

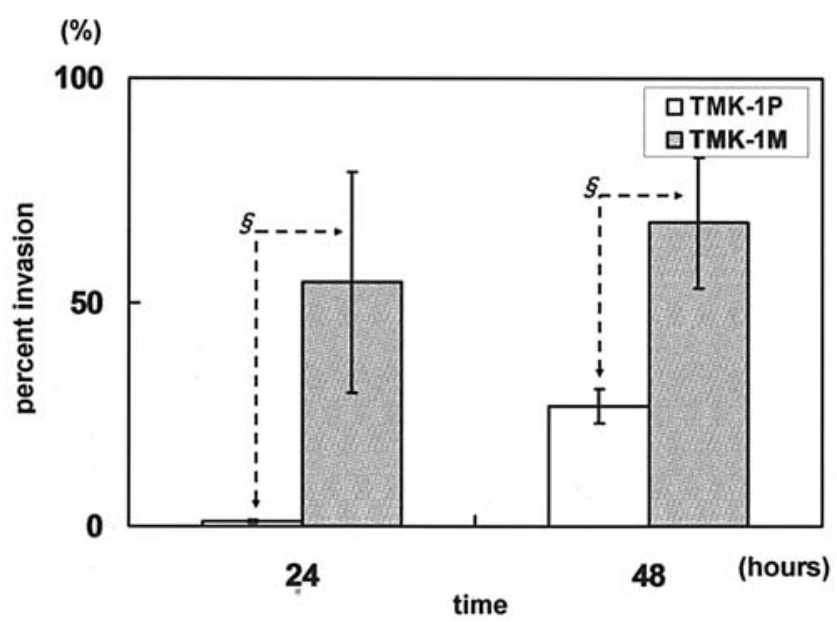

Figure 9. Matrigel invasion assay. The percent invasion is higher in TMK-1M than in TMK-1P at 24 and $48 \mathrm{~h}$. Bars represent standard errors of the mean. ${ }^{\S} \mathrm{P}<0.05$ when compared using Student's t-test. intensity of either Cy3 or Cy5 was $>10000$ ) are listed in Table II. A marked differential expression was observed in genes related to cell-cell adhesion and the extracellular matrix molecules of which hexabrachion (tenascin-C), CDH6, $\beta 1$-catenin, and $\alpha$ disintegrin and metalloproteinase domain 9 (ADAM9) genes were up-regulated, and the $67 \mathrm{kDa}$ laminin receptor 1 and transforming growth factor (TGF)- $\beta$-induced $68 \mathrm{kDa}$ protein (Big-h3) genes were down-regulated in TMK-1P. The genes of the growth factor-related molecules EGFR and insulin-like growth factor 2 receptor and the insulin-like growth factor binding protein-3 gene were downregulated in TMK-1M. Villin 2 was up-regulated in TMK-1P. Among other genes not listed in Table I, the vimentin and urokinase genes were up-regulated in TMK-1M.

To verify the difference between the gene expression at the mRNA level observed in the microarray, we selected representative genes (tenascin $C, E G F R, C D H 6, \beta 1$-catenin, $67 \mathrm{kDa}$ laminin receptor 1 gene and $\beta i g-h 3)$ for real-time RT-PCR analysis. $\Delta \mathrm{Ct}$ values and fold difference based on real-time RT-PCR analysis are shown in Fig 10. The same

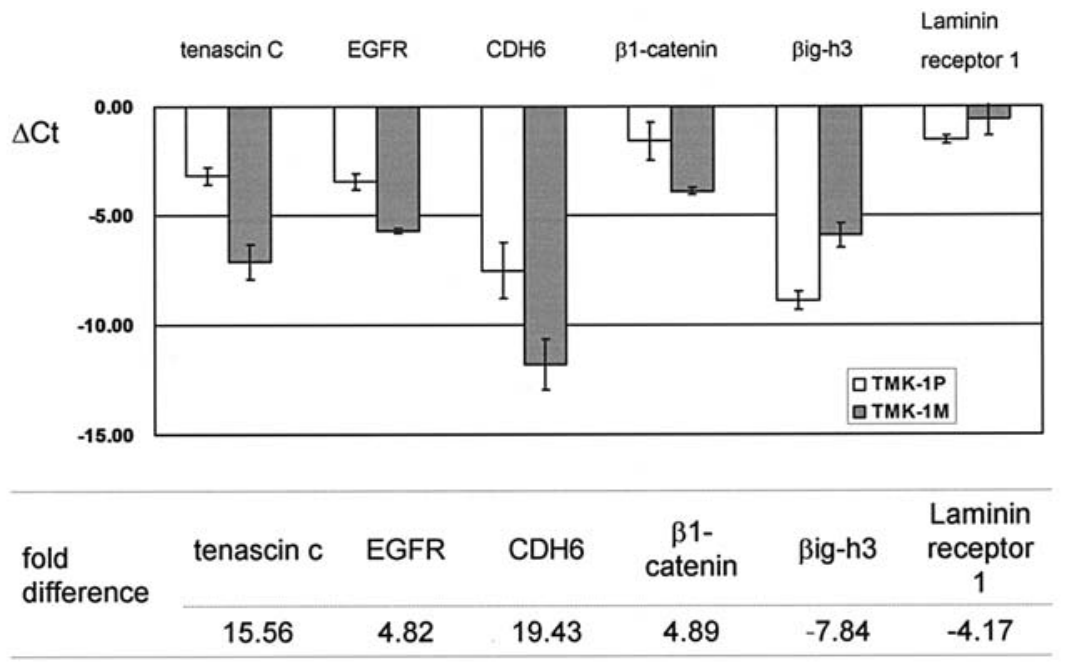

Figure 10. Gene expression at the mRNA level determined by real-time RT-PCR. Negative values of fold difference indicate a level of mRNA in TMK-1P lower than that in TMK-1M. The bars represent the standard errors of the mean. EGFR, epidermal growth factor receptor; CDH6, cadherin-6 and Big-h3, transforming growth factor (TGF)-ß3-induced 68-kDa protein. 
Table II. The major differential genes between TMK-1P and TMK-1M.

\begin{tabular}{lccc}
\hline Gene & $\begin{array}{c}\text { Cy3/Cy5 ratio } \\
\text { Fold change }\end{array}$ & $\begin{array}{c}\text { Intensity of Cy3 } \\
\text { (TMK-1P) }\end{array}$ & $\begin{array}{c}\text { Intensity of Cy5 } \\
\text { (TMK-1M, normalized) }\end{array}$ \\
\hline Hexabrachion (tenascin C) & 24.08 & 43152 & 1791 \\
Epidermal growth factor receptor & 16.10 & 26938 & 1673 \\
$\alpha$ disintegrin and metalloproteinase domain 9 (ADAM9) & 7.20 & 11844 & 1644 \\
B1-catenin & 4.23 & 10317 & 2437 \\
Cadherin-6 & 4.06 & 26863 & 6621 \\
G1 to S phase transition 1 & 3.78 & 4099 \\
Cyclin G1 & 3.69 & 15496 & 4154 \\
LPS-induced TNF- $\alpha$ factor & 3.60 & 15335 & 4162 \\
CD59 antigen p18-20 & 3.09 & 14983 & 7821 \\
Villin 2 (ezrin) & 2.88 & 24155 & 4608 \\
Signal transducer and activator of transcription 1,91 kDa & 2.87 & 13264 & 4404 \\
Retinoblastoma-binding protein 4 & 2.87 & 12634 & 4922 \\
Receptor tyrosine kinase-like orphan receptor 1 & 2.62 & 14113 & 4403 \\
Insulin-like growth factor binding protein 3 & 2.59 & 11516 & 18620 \\
Insulin-like growth factor 2 receptor & 2.45 & 48139 & 4542 \\
Transforming growth factor, B-induced, 68 kDa (Big-h3) & 0.33 & 11111 & 5604 \\
Laminin receptor 1 (67 kDa) & 0.32 & 5087 & 25797 \\
\hline
\end{tabular}

significant differences in gene expression were observed by real-time RT-PCR analysis. However, the fold change in the expression level obtained by these two different analytical methods was not exactly the same. These results support the findings obtained from the microarray experiments.

Expression of hypoxia-inducible factor pathway genes. The RT-PCR analysis showed that the two cell lines expressed $\mathrm{VEGF}_{121}$ and $\mathrm{VEGF}_{165} \mathrm{mRNA} \mathrm{VEGF}_{189}$ and $\mathrm{VEGF}_{206} \mathrm{mRNA}$ was not detected in the two cell lines. VEGFR-2 mRNA was detected in only TMK-1M. HIF-1 $\alpha$ mRNA was detected in the two cell lines, whereas CA9 mRNA was not detected in either cell line (Fig. 11).

\section{Discussion}

In this study, we established the RCC cell lines, TMK-1P and TMK-1M, from a matched primary tumor and adrenal metastasis from the same RCC patient. The existence of cell surface microvilli and tight junctions observed by electron microscopy confirmed their epithelial origin.

DNA microarray analysis revealed that 149 genes showed an increased and 17 genes a decreased signal intensity in TMK-1P versus those in TMK-1M. The results of real-time RT-PCR analyses supported the differences in the 6 representative genes observed in the microarray experiments. Most of the genes exhibiting an increased signal intensity were those related to growth factors, cell division and signal transduction. The differential gene expression was closely related to the rapid growth rate of TMK-1P. Additionally, microarray analysis demonstrated a decreased expression of the EGFR and cadherin- 6 genes and an increased expression of the vimentin gene in TMK-1M versus those in TMK-1P. Cadherin-6 is a cell-cell adhesion molecule and is expressed

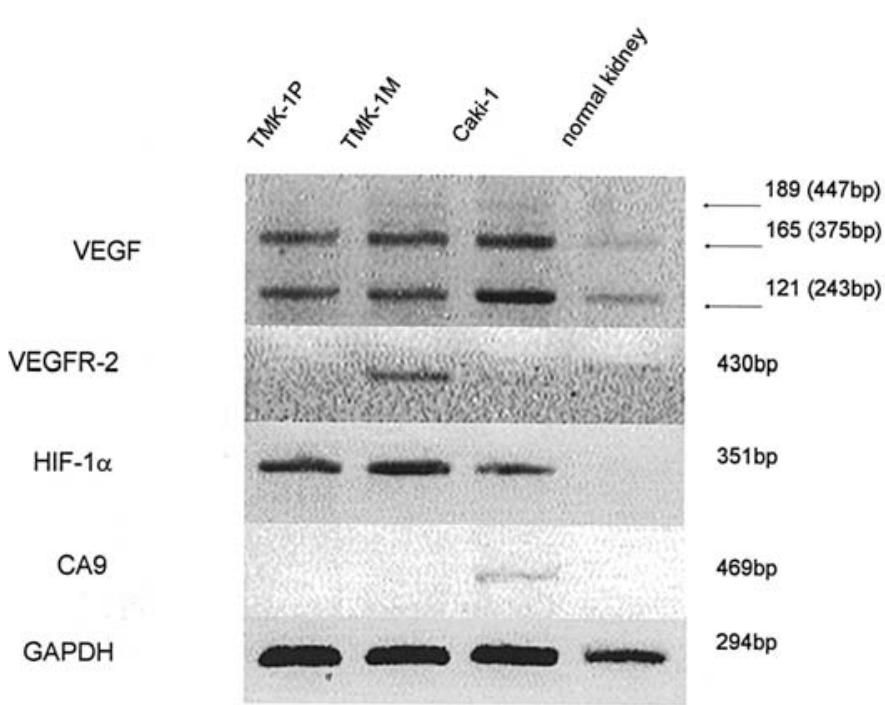

Figure 11. Expression of hypoxia-inducible factor pathway genes. RT-PCR analysis showed that the two cell lines expressed $\mathrm{VEGF}_{121}$ and $\mathrm{VEGF}_{165}$ mRNA. $V_{E G F}$ and $V_{189} F_{206}$ mRNA was not detected in either cell line. VEGFR-2 mRNA was detected in only TMK-1M. HIF- $1 \alpha$ mRNA was detected in the two cell lines. CA9 mRNA was not detected in either cell line.

in the renal proximal tubular epithelium, from where clear cell RCC is believed to arise. It is reported that loss of cadherin- 6 expression is more common in high-grade tumors and tumors with a poor prognosis (12). The differential expression of these genes indicated that TMK-1M had lost their epithelial features and developed features similar to those of mesenchymes. The observation from an ultrastructural study that TMK-1M has fewer microvilli than TMK-1P indicated that TMK-1M tends to lose the 
characteristics of the proximal tubular cells. Villin 2 (Ezrin) functions as a cross-linker protein between the actin cytoskeleton and the plasma membrane and is involved in microvilli formation (13). The decreased expression of Villin 2 in TMK-1M may be correlated with the observations from the ultrastructural study.

The growth rate of TMK-1M was slower than that of TMK-1P. In contrast, the Matrigel invasion assay demonstrated the higher invasive ability of TMK-1M. The difference in the invasive ability may also be explained by the differential gene expression. TMK-1M showed an increased expression of the $67 \mathrm{kDa}$ laminin receptor and $\beta i g-h 3$ genes in DNA microarray analysis. The $67 \mathrm{kDa}$ laminin receptor, a lamininbinding protein, acts as an accessory molecule to stabilize the binding of the $\alpha 6 \beta 4$ integrin to laminin (14). It has been reported that the $67 \mathrm{kDa}$ laminin receptor has additional functions including the degradation of laminin-1 and the invasiveness of the two cell lines through Matrigel $(15,16)$. The ECM protein Big-h3 that is induced by TGF- $\beta$ is involved in cell adhesion, cell motility and proliferation through $\alpha 634$ or $\alpha 3 ß 1$-integrin action $(17,18)$. Regarding its biological role in cancer, although the increased expression of Big-h3 mRNA was reported in several tumor types, its function remains unclear $(19,20)$. The differential expression of the 67-kDa laminin receptor and $\beta i g-h 3$ genes may have influenced the invasive ability of the cell lines through Matrigel.

Advances in the molecular biology of RCC have led to the development of new agents targeting critical gene products downstream of pVHL and the hypoxia-inducible factor pathway, such as the vascular endothelial growth factor and epidermal growth factor receptor (6). It was found that TMK-1M expressed the VEGFR gene. These novel cell lines may be useful for studying tumor invasion and for moleculartargeted therapy.

\section{Acknowledgements}

This work was partially supported by a 'High-Tech Research Center' Project for private universities and a matching fund subsidy from MEXT (Ministry of Education, Culture, Sports, Science and Technology, 2003-2007).

\section{References}

1. Landis SH, Murray T, Bolden S and Wingo PA: Cancer statistics. CA Cancer J Clin 49: 8-31, 1999.

2. deKernion JB and Belldegrun A: Renal tumors. In: Campbell's Urology. Walsh PC, Retik AB, Stamey TA, Vaughan ED (eds). WB Saunders Company, Philadelphia, pp1053-1093, 1999.

3. Maldazys JD and deKernion JB: Prognostic factors in metastatic renal carcinoma. J Urol 136: 376-379, 1986.
4. Murphy WM, Beckwith JB and Farrow GM: Tumors of the kidney. In: Atlas of Tumor Pathology. Rosai J (ed). Vol. 11, Armed Forces Institute of Pathology, Washington DC, pp1-180, 1994.

5. Bleumer I, Oosterwijk E, de Mulder P and Mulders PF: Immunotherapy for renal cell carcinoma. Eur Urol 44: 65-75, 2003.

6. Rini B and Small EJ: Biology and clinical development of vascular endothelial growth factor-targeted therapy in renal cell carcinoma. J Clin Oncol 23: 1028-1043, 2005.

7. Nakamura H, Saji H, Ogata A, et al: cDNA microarray analysis of gene expression in pathologic stage IA non-small cell lung carcinomas. Cancer 97: 2798-2805, 2003.

8. Yoshinaga $\mathrm{K}$, Inoue $\mathrm{H}$, Utsunomiya $\mathrm{T}$, et al: $\mathrm{N}$-cadherin is regulated by activin $\mathrm{A}$ and associated with tumor aggressiveness in esophageal carcinoma. Clin Cancer Res 10: 5702-5707, 2004.

9. Luu-The V, Paquet N, Calvo E and Cumps J: Improved realtime RT-PCR method for high-throughput measurements using second derivative calculation and double correction. Biotechniques 38: 287-293, 2005.

10. Hamalainen H, Zhou H, Chou W, Hashizume H, Heller R and Lahesmaa R: Distinct gene expression profiles of human type 1 and type 2 Thelper cells. Genome Biol 2: Research 0022.1-0022.11, 2001.

11. Tomisawa M, Tokunaga T, Oshika Y, et al: Expression pattern of vascular endothelial growth factor isoform is closely correlated with tumour stage and vascularisation in renal cell carcinoma. Eur J Cancer 35: 133-137, 1999.

12. Paul R, Nicknig U, Busch R, Ewing CM, Hartung R and Isaacs WB: Cadherin-6: a new prognostic marker for renal cell carcinoma. J Urol 171: 97-101, 2004.

13. Bretscher A, Reczek D and Berryman M: Ezrin: a protein requiring conformational activation to link microfilaments to the plasma membrane in the assembly of cell surface structures. J Cell Sci 110: 3011-3018, 1997

14. Ardini E, Tagliabue E, Magnifico A, Buto S, Castronovo V, Colnaghi MI and Menard S: Co-regulation and physical association of the $67-\mathrm{kDa}$ monomeric laminin receptor and the alpha6beta4 integrin. J Biol Chem 272: 2342-2345, 1997.

15. Ardini E, Sporchia B, Pollegioni L, et al: Identification of a novel function for 67-kDa laminin receptor: increase in laminin degradation rate and release of motility fragments. Cancer Res 62: 1321-1325, 2002.

16. Givant-Horwitz V, Davidson B and Reich R: Laminin-induced signaling in tumor cells: the role of the $M(r) 67,000$ laminin receptor. Cancer Res 64: 3572-3579, 2004.

17. Kim MO, Yun SJ, Kim IS, Sohn S and Lee EH: Transforming growth factor-beta-inducible gene-h3 (beta(ig)-h3) promotes cell adhesion of human astrocytoma cells in vitro: implication of alpha6beta4 integrin. Neurosci Lett 336: 93-96, 2003.

18. Bae JS, Lee SH, Kim JE, et al: Beta ig-h3 supports keratinocyte adhesion, migration, and proliferation through alpha3beta 1 integrin. Biochem Biophys Res Commun 294: 940-948, 2002.

19. Aitkenhead M, Wang SJ, Nakatsu MN, Mestas J, Heard C and Hughes CC: Identification of endothelial cell genes expressed in an in vitro model of angiogenesis: induction of ESM-1, (beta)ig-h3, and NrCAM. Microvasc Res 63: 159-171, 2002.

20. Schneider D, Kleeff J, Berberat PO, Zhu Z, Korc M, Friess H and Buchler MW: Induction and expression of betaig-h3 in pancreatic cancer cells. Biochim Biophys Acta 1588: 1-6, 2002. 